\title{
Pengembangan Kompetensi Guru dalam Pembelajaran PAI bagi Generasi Z
}

\author{
Sari Narulita ${ }^{1}$, Rihlah Nur Aulia ${ }^{2}$, M Rudi Barnansyah $^{3}$, Aminah $^{4}$, M Zaki as Suminar ${ }^{5}$ \\ ${ }_{1,2,3,4,5}$ Pendidikan Agama Islam, Fakultas Ilmu Sosial, Universitas Negeri Jakarta \\ ${ }^{1}$ sari-narulita@unj.ac.id \\ ${ }^{2}$ rihlah-nuraulia@unj.ac.id \\ ${ }^{3}$ rudibarnansyah@unj.ac.id \\ ${ }^{4}$ aminah_pai17s1@mahasiswaunj.ac.id \\ 5aki_PAI18s1@mahasiswa.unj.ac.id
}

\begin{abstract}
ABSTRAK
Generasi muda saat ini atau yang disebut dengan generasi $\mathrm{Z}$ merupakan generasi yang lahir setelah tahun 2000 hingga saat ini dan sangat lekat dengan gadget. Kemudahan yang mereka miliki dalam mengakses media, sayangnya tidak dibarengi dengan kemampuan filter yang kuat untuk dapat memilah dan memilih informasi yang di terimanya. Oleh karena itu, guru masa kini perlu mempersiapkan diri dengan mengembangkan kompetensinya. Solusi yang ditawarkan adalah pengembangan kompetensi pendidik, baik guru PAI (Pendidikan Agama Islam) untuk bisa memahami anak didiknya, yang umumnya berasal dari generasi $\mathrm{Z}$ agar proses pembelajaran PAI menjadi efektif. Kegiatan pengabdian ini bertujuan untuk membantu guru maupun calon guru dalam meningkatkan pemahaman dan kesadaran serta strategi dalam menciptakan proses pembelajaran PAI yang menarik bagi generasi Z. Pelaksanaan kegiatan berbentuk workshop terkait komunikasi efektif antara guru dan murid, urgensi PAI dalam membentuk karakter, pengenalan karakteristik generasi Z serta strategi pembelajaran PAI bagi generasi $\mathrm{Z}$ dan ditutup dengan sessi share and care. Workshop dilakukan dengan metode interaktif, antara narasumber dan peserta dan ditunjang dengan sessi share and care yang memperkuat dan meningkatkan pengalaman dan wawasan para guru dan calon guru tentang bagaimana menangani generasi $\mathrm{z}$ dalam proses pembelajaran.PAI
\end{abstract}

Kata kunci: Pendidikan Agama Islam, Generasi Z, Kompetensi Guru

\begin{abstract}
The current young generation or the so-called the $Z$ generation is a generation born after 2000 until now and is very attached to gadgets. The ease that they have in accessing media, unfortunately, is not accompanied by a strong filter ability to be able to sort and select the information they receive. Therefore, today's teachers need to prepare themselves by developing their competencies to handle it. The solution offered is the development of the competence of PAI (Islamic religious education) teachers to be able to understand their students, who generally come from $Z$ generation so that the learning process of PAI becomes effective. This service activity aims to help teachers and prospective teachers in increasing their understanding, awareness, and strategies in creating a PAI learning process that is interesting for the $Z$ Generation. The implementation of activities in the form of workshops related to effective communication between teacher and students, the urgency of PAI in shaping character, introduction of the characteristics of the Z Generation and PAI learning strategies for the Z Generation and closed with a share and care session. The workshop was conducted using an interactive method, between speakers and participants and supported by an assembly of sharing and care that strengthens and enhances the experiences and insights of teachers and prospective teachers on how to handle the $Z$ generation in the Islamic religious education learning process.
\end{abstract}

Kata kunci: Islamic Religious Education, Z Generation, Teacher Competencies 


\section{PENDAHULUAN}

Berkembangnya teknologi pada masa kini mulai memicu ketergantungan kepada koneksi internet. Pada awalnya, ketergantungan generasi $\mathrm{Z}$ terhadap kecanggihan teknologi, informasi, dan transformasi dianggap sebagai media atau alat untuk mempermudah aktivitasnya. Namun, efek sampingnya mulai tampak, dimana dunia generasi $\mathrm{Z}$ sudah berada di dunia maya dan cenderung mengabaikan dunia nyata atau realita disekitarnya.

Generasi Z merupakan generasi yang lahir pada tahun 2000 hingga saat ini. Secara umum, generasi $\mathrm{Z}$ memiliki konsep berpikir global, berkomunikasi secara digital dan menyukai hal yang bersifat visual. Karenanya mereka menyukai berbagai media yang mengkombinasikan tulisan, gambar dan video untuk mengekspresikan diri mereka. Media yang dimaksud diantaranya Facebook, Instagram, Line dll. Berdasarkan penelitian hinduan diketahui bahwa generasi $\mathrm{Z}$ banyak menggunakan smartphone untuk menggunakan medsos. (Hinduan, ZR; Agia, 2017)

Kemudahan yang mereka miliki dalam mengakses media, sayangnya tidak dibarengi dengan kemampuan filter yang kuat untuk dapat memilah dan memilih informasi yang di terimanya. Oleh karena itu, guru masa kini perlu mempersiapkan diri dengan memperbaiki sikap dan kompetensinya, sehingga menjadi figur yang menginspirasi peserta didiknya.(Mucharomah, 2017)

Selain itu, terbatasnya fokus generasi $\mathrm{Z}$ seolah tidak banyak dipahami. Sehingga terkesan, generasi $\mathrm{Z}$ lebih fokus pada handphonenya atau hal lainnya dibandingkan materi yang diterimanya. Hal inilah yang tidak banyak dipahami oleh para pendidik.

Peran guru yang sangat diperlukan dalam membekali dan membentuk kepribadian anak didik masa kini semakin berat. Hal ini disebabkan, Pertama, guru yang lahir pada era revolusi industri ketiga harus mengajar generasi $\mathrm{Z}$ dengan perkembangan teknologinya. Karenanya, Guru tidak boleh gagap teknologi. Komputer dan gawai harus sudah menjadi keseharian para guru. Media sosial dan berbagai sumber informasi maupun sosialisasi juga harus dipahami para guru sehingga dalam guru akan kaya dengan materi maupun metode pembelajaran. Siswa pun tidak akan menganggap remeh guru.

Kedua, Guru harus mampu menjaga karakter kebangsaan dalam dirinya yang potensial terkikis oleh berbagai ideologi mulai dari hedonisme hingga radikalisme. Hal tersebut ditandai dengan munculnya asumsi bahwa banyak guru agama yang tidak mengajarkan toleransi, pentingnya hidup berdampingan secara damai, dan nilai-nilai Pancasila sebagai fondasi kehidupan negara; pada diri siswa ditanamkan nilai-nilai eksklusif yang menekankan bahwa di luar keyakinannya adalah kafir. Bahkan tak jarang, di media sosial, guru malah ikut serta dalam gelombang ujaran kebencian atau ikut serta menyebarkan berita bohong. Intoleransi telah menyebar bukan hanya pada warga biasa yang minim pendidikan, melainkan juga mereka yang terpelajar, termasuk para guru.

Tantangan di atas akan semakin berat bila guru tidak mampu memahami dan beradaptasi dengan gaya hidup generasi $\mathrm{Z}$. Karenanya, dibutuhkan pengembangan kompetensi guru dalam mendidik generasi $\mathrm{Z}$. Pengajaran, strategi dan metode pembelajaran harus berubah disebabkan perubahan komposisi siswa dan juga perubahan lingkungan kerja.

Terlebih, tujuan pendidikan menghendaki adanya perubahan perilaku dan sikap serta kualitas seseorang, maka pengajaran harus berlangsung sedemikian rupa sehingga tidak sekedar memberi informasi atau pengetahuan melainkan harus menyentuh hati, dan mendorong hasrat peserta didik untuk bisa mengambil keputusan berubah, dan mempraktekkannya langsung sepanjang kehidupan manusia. Implementasi dilakukan karena sejatinya, siswa yang mempelajari PAI hendaknya tidak sekedar memahami sisi kognitifnya saja; namun juga mampu membuatnya menjiwai pada tingkat kesadaran paling dalam melalui internalisasi nilai agama dalam dirinya. (Novayani, 2017)

Dengan demikian, maka bisa dilihat bahwa kelompok sasaran (Pendidik Agama) banyak yang memerlukan pengembangan kompetensi agar lebih mampu memberikan wawasan keagamaan dengan lebih efektif dan juga menjadi inspirasi bagi anak didiknya

Tujuan dari pelaksanaan pengabdian ini yaitu: 1). Meningkatkan pengetahuan peserta guru dan calon guru tentang karakteristik generasi Z. 2). Membantu peserta guru dan calon guru dalam menentukan strategi yang tepat untuk proses pembelajaran yang efektif bagi generasi Z. 3). Meningkatkan 
pengetahuan/ wawasan peserta guru dan calon guru untuk meningkatkan komunikasi efektif antara guru dan murid.

\section{METODE KEGIATAN}

Pendaftaran peserta dibuka secara online dan terbatas hanya untuk 20 (dua puluh peserta) guru PAI di DKI Jakarta dengan tujuan agar workshop bisa berjalan secara optimal. Dalam waktu kurang dari 2 (dua) hari, peserta workshop, yakni guru PAI di DKI Jakarta terpenuhi kuotanya.

Pelaksanaan kegiatan berlangsung pada tanggal 13 Juli 2019 bertempat di di Gedung Syafi'I lantai 8 Universitas Negeri Jakarta. Materi yang disampaikan berfokus pada Komunikasi Efektif Guru dan Murid, Urgensi PAI dalam pembentukan karakter, Mengenal Karakteristik Generasi Z, dan Strategi Pembelajaran PAI bagi Generasi Z. Kegiatan di lengkapi dengan Sharing pengalaman tindakan dan strategi penanganan generasi $\mathrm{Z}$ di kelas.

Kegiatan mulai dilaksanakan pada pukul 08.00 WIB untuk registrasi peserta guru dan calon guru dan acara dibuka pada 08.30 WIB dengan agenda sambutan dan pembukaan acara pelatihan. Pada pukul 09.00-10.00 WIB pemberian materi pertama yaitu Komunikasi Efektif Guru dan Murid yang disampaikan oleh Dr. Nugrahaeni, Dosen Prodi Ilmu Komunikasi Fakultas Ilmu Sosial UNJ pada pukul 10.00 - 11.00 WIB. Dilanjutkan dengan materi kedua yaitu materi Urgensi PAI dalam pembentukan karakter yang disampaikan Oleh Dr. Andy Hadiyanto, dosen senior Sesi ketiga pada pukul 11.00-12.00 dilanjutkan materi ketiga Mengenal Karakteristik Generasi Z yang disampaikan Oleh Sari Narulita, M.Si Setelah break, materi dilanjutkan pada pukul 13.00-14.00 oleh M. Rudi Barnansyah, M.Pd.I dengan materi Strategi Pembelajaran PAI bagi Generasi Z. Setelahnya, dibagi kelompok dalam sessi share and care, dimana para peserta berbagi pengalaman dalam mengajar Generasi $\mathrm{Z}$ di sekolahnya masing-masing. kegiatan ditutup pada pukul 15.30 dengan pembagian sertifikat.

Proses workshop berlangsung secara interaktif, terutama pada saat sesi share \& care dimana para guru dan calon guru dapat berbagi pengalaman satu sama lain mengenai strategi yang tepat untuk menangani generasi $\mathrm{Z}$. Pada sesi, peserta calon guru dan guru dibagi menjadi 2 (dua) kelompok dan masing-masing kelompok mengemukakan strategi yang seharusnya diterapkan untuk proses pembelajaran yang efektif bagi Generasi Z .

\section{HASIL \& PEMBAHASAN}

Indikator keberhasilan dapat dilihat melalui dua cara, yaitu evaluasi proses dan feedback respon akan implementasi dari materi yang diserap, 1 (satu) bulan setelah workshop dilaksanakan. Evaluasi proses dilakukan melalui pengisian kuesioner oleh peserta terkait kegiatan yang telah dilakukan; mencakup urgensi materi, penyampaian materi dan juga kesiapan sarana dan prasarana. Sedangkan evaluasi akan dampak kegiatan dilakukan dengan cara membuat whatsapps grup bagi para peserta sebagai sarana komunikasi dan sarana untuk berbagai ide dan inspirasi sesame peserta. Peserta pun diarahkan untuk menuliskan pengalaman terkait implementasi strategi yang telah dipaparkan pada saat workshop di kelas.

Evaluasi proses mengacu kepada tanggapan atas materi, penyampaian serta fasilitas. Secara umum, para peserta mengungkapkan bahwa materi yang dipaparkan narasumber cukup berkesan karena bersifat aplikatif serta menyertakan permasalahan yang real dalam pembelajaran. Selain itu materi yang dipaparkan juga dipandang dapat memecahkan masalah yang selama ini terjadi pada saat kegiatan pembelajaran di kelas. Salah satu materi yang menjadi perhatian peserta adalah terkait dengan strategi pembelajaran PAI di era industry 4.0 dan cara menarik perhatian generasi $Z$. Hal tersebut membuat peserta tertarik untuk meningkatkan kemampuan mengajarnya agar materi yang disampaikan bisa dipahami dengan baik oleh siswa, generasi Z.

Peserta pun mengkonfirmasi bahwa materi yang diberikan mampu menambah wawasan terkait pembelajaran bagi generasi $\mathrm{Z}$. Peserta menjadi lebih mengerti tentang dunia generasi $\mathrm{Z}$ yang sangat lekat dengan gadget dan terinspirasi untuk menjadikan gadget sebagai bagian dari proses pembelajaran; dan tidak menjadikannya sebagai penghambat dalam proses pembelajaran selama mampu dikelola penggunaannya dengan baik. Peserta juga menegaskan bahwa pelatihan tersebut menjadikan mereka lebih siap untuk membuat proses pembelajaran yang kritis, kreatif inovatif dan kolaboratif. 
Tabel 1. Hasil Evaluasi Proses

\begin{tabular}{lcccc}
\hline \multicolumn{1}{c}{ Unsur yang dinilai } & $\begin{array}{c}\text { Sangat Tidak } \\
\text { Memuaskan (\%) }\end{array}$ & $\begin{array}{c}\text { Tidak } \\
\text { Memuaskan (\%) }\end{array}$ & Memuaskan (\%) & $\begin{array}{c}\text { Sangat } \\
\text { Memuaskan (\%) }\end{array}$ \\
\hline Materi & 0 & 0 & $7 \%$ & $93 \%$ \\
\hline Penyampaian materi & 0 & 0 & $21 \%$ & $79 \%$ \\
\hline Penyediaan fasilitas & 0 & 0 & $14 \%$ & $86 \%$ \\
\hline
\end{tabular}

Tabel di atas menunjukkan tingkat kepuasan peserta akan kegiatan yang dilaksanakan dan peserta tidak memberikan respon yang negatif akan kegiatan yang ada. Mereka hanya mempermasalahkan keterbatasan waktu disaat Materi yang ada sangat menarik untuk dibahas lebih lanjut. Peserta pun berharap bahwa kegiatan serupa bisa dilakukan guna merefresh pemahaman dan semangat para guru dalam mengajar. Terlebih, dengan adanya sessi share \& care, peserta menjadi saling berbagi pengalaman, ide dan inspirasi untuk menciptakan proses pembelajaran PAI yang lebih kritis, kreatif, inovatif dan kolaboratif.
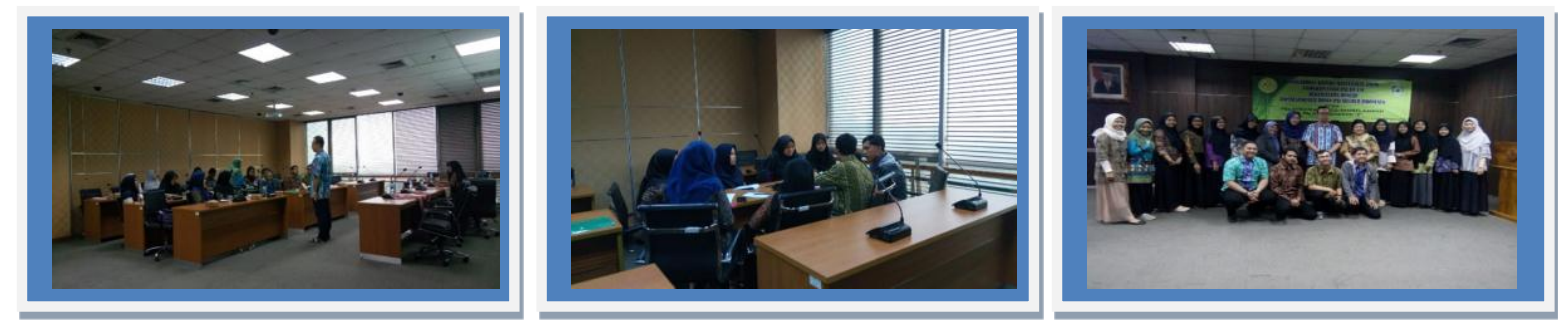

\section{Gambar 1. Foto kegiatan}

Setelah kegiatan berakhir, peserta tetap membangun komunikasi melalui whatsapp grup dan tetap saling mensupport dan memotivasi diantara mereka. Setelah satu bulan, peserta menuliskan pengalaman akan implementasi materi dalam proses pembelajaran dan peserta merasakan perubahan yang cukup signifikan saat menjalankan strategi yang diramu Bersama; para siswa menjadi antusias dalam proses belajar mengajar, kegiatan mengajarpun menjadi lebih interaktif dan tujuan yang akan disampaikan menjadi lebih efektif.

\section{KESIMPULAN \& SARAN}

Untuk menghasilkan pembelajaran yang efektf di dalam kelas, seorang guru -yang dalam hal ini guru PAI- hendaknya memahami karakteristik siswa saat ini yang didominasi oleh generasi $\mathrm{Z}$, yang lekat dengan gadget dan informasi yang berlimpah.

Dengan memahami karakteristik generasi $\mathrm{Z}$ dengan kemampuannya dalam mengakses informasi, maka guru tidak sepenuhnya menjadi sumber, namun lebih menjadi fasilitator hingga siswa mampu memilah informasi yang valid dan akurat. Guru pun hendaknya mampu menjadi teladan bagi siswanya agar siswa lebih mudah menyerap lebih baik akan Materi yang disampaikan. (Narulita et al., 2019)

Metode pembelajaran yang digunakan dalam Pendidikan Agama Islam khususnya di lembaga pendidikan formal umumnya hanya bersifat teknis dan operasional sehingga materi pembelajaran Pendidikan Agama Islam mengalami involusi artinya penyampaian materi pendidikan selalu menoton dan statis. Maka dari itu, diperlukan pengembangan model-model pembelajaran yang dapat memberikan kesempatan kepada siswa untuk lebih aktif dan terlibat dalam proses pembelajaran.(Mukaffan, 2013), dan hal tersebut hanya akan bisa dilakukan bila guru mampu memahami karakteristik generasi Z.

Pengembangan kompetensi dalam pembelajaran PAI bagi generasi $\mathrm{Z}$ perlu rutin dilakukan, agar guru selalu mampu kreatif dalam menciptakan pembelajaran yang membuat siswa lebih kritis.kreatif., inovatif 
dan juga kolaboratif. Pengembangan dilakukan dalam berbagai bentuk, baik itu workshop, pelatihan, seminar ataupun sekedar berbagi pengalaman, ide dan inspirasi sesama teman sejawat.

\section{DAFTAR PUSTAKA}

Hinduan, ZR; Agia, M. K. (2017). Generation $Z$ in Indonesia; Psychological Capital. Work Value and Learning Syles. Bandung: Universitas Padjajaran.

Mucharomah, M. (2017). Guru di Era Milenia dalam Bingkai Rahmatan Lil Alamin. Edukasi Islamika, 2(2), 201-221.

Mukaffan. (2013). Trend Edutainment dalam metode Pembelajaran PAI. Tadris; Jurnal Pendidikan Islam, 8(2), 306-320.

Narulita, S., Aulia, R. N., Nugrahaeni, E., Wajdi, F., Mardhiah, I., \& Hadiyanto, A. (2019, August). Religion Learning Strategies for the Z Generation BT - 1st International Conference on Education Social Sciences and Humanities (ICESSHum 2019). Retrieved from https://www.atlantispress.com/article/125914745

Novayani, I. (2017). Pembelajaran PAI berbasis Multikultural. Tadrib, 3(2), 235250. 